\title{
Preparation of Fibrous Titania Oxynitride - Carbon Catalyst and Oxygen Reduction Reaction Analysis in Both Acidic and Alkaline Media
}

\author{
Taro Kinumoto*, Yoshinori Sou, Kohei Ono, Miki Matsuoka, \\ Yasuhiko Arai, Tomoki Tsumura, and Masahiro Toyoda \\ Department of Applied Chemistry, Faculty of Engineering, Oita University, \\ 700 Dannoharu, Oita, 870-1192, Japan
}

*Corresponding author: Taro KINUMOTO

Tel. \& Fax: +81-97-554-7905

E-mail: kinumoto@oita-u.ac.jp 


\section{Abstract}

A fibrous catalyst of titania oxynitride and carbon is prepared and its catalytic behavior in the oxygen reduction reaction (ORR) are investigated in both $\mathrm{HClO}_{4}$ and $\mathrm{KOH}$ aqueous solutions. $\mathrm{TiO}_{2}$ particles are successfully deposited on activated carbon fibers by a liquid phase deposition technique using $\left(\mathrm{NH}_{4}\right)_{2} \mathrm{TiF}_{6}$ and $\mathrm{H}_{3} \mathrm{BO}_{3}$. The catalyst obtained after subsequent ammonia nitridation at $1273 \mathrm{~K}$ had a fibrous structure with $\mathrm{TiO}_{\mathrm{x}} \mathrm{N}_{\mathrm{y}}$ and $\mathrm{TiN}$ components as titania families.

Interestingly, the product demonstrates catalytic activity for the ORR in not only $\mathrm{HClO}_{4}$ but also $\mathrm{KOH}$ aqueous solution. The onset potential in $\mathrm{HClO}_{4}$ solution is assumed to be moderate, at $0.85 \mathrm{~V}$; on the other hand, that in $\mathrm{KOH}$ solution is relatively high at $0.95 \mathrm{~V}$. Furthermore, it is considered from the Tafel plot analysis of the $\mathrm{KOH}$ solution results that the ORR mechanism follows a peroxide intermediate pathway and the rate-determining step would be a one-electron-transfer reaction to oxygen molecules adsorbed on the active site.

\section{Keywords:}

Electrode catalyst, Oxygen reduction reaction, Fibrous, Carbon, Titania oxynitride 


\section{Introduction}

Electrochemical power sources that use oxygen as a reactant will be indispensable for society's future energy needs. In particular, fuel cells, metal-air batteries, and hydrogen-air batteries are typical, and hold promise as the power sources for electric vehicles and stationary power generators [1-3].

However, challenges remain for the development of highly active catalysts (i.e., with low activation overpotentials) for oxygen electrode reactions, such as the oxygen reduction reaction (ORR; a discharge reaction) and oxygen evolution reaction (OER; a charge reaction). Despite over a century of catalyst exploration, Pt group elements and their alloys remain the most active electrode catalysts for the ORR, showing the lowest activation overpotentials in both acid and alkaline media [4-6].

Even with the best Pt-based electrode catalysts available, an overpotential exceeding $0.3 \mathrm{~V}$ is usually observed when an appreciable current for the ORR is generated in acidic as well as alkaline medium [4-6]. Furthermore, the low global abundance of $\mathrm{Pt}$ is also cause for concern. Use of $\mathrm{Pt}$ as an electrode catalyst remains a bottleneck for the realization of our clean energy goals. Therefore, an active electrode 
catalyst that can replace $\mathrm{Pt}$, is highly abundant, and exhibits a low activation overpotential is being actively sought by many researchers.

The catalytic activity of titania oxynitride $\left(\mathrm{TiO}_{\mathrm{x}} \mathrm{N}_{\mathrm{y}}\right)$ for the ORR in acidic aqueous solution was first reported by Ota et al. [7, 8]. The natural abundance of Ti, O, and $\mathrm{N}$ is much higher than that of Pt. Recently, challenges for group 4 and 5 metal oxide-based catalysts have also been carried out [9]. A carbon alloy has also shown promise for the ORR in acid solution [10]. Unfortunately, these materials exhibit insufficient catalytic activity, and Pt's current superiority makes it the most commonly used.

We are interested in the study of highly active ORR catalysts composed of abundant elements. Therefore, in this study, the preparation and catalytic properties of a titanium oxynitride-carbon $\left(\mathrm{TiO}_{\mathrm{x}} \mathrm{N}_{\mathrm{y}}-\mathrm{C}\right)$ catalyst with a fibrous morphology are reported. A fibrous structure affords higher power output in fuel cells because of superior gas diffusion properties $[11,12]$. The catalyst was prepared by loading $\mathrm{TiO}_{2}$ particles on carbon fibers via a liquid phase deposition (LPD) technique followed by ammonia nitridation. Specifically, $\left(\mathrm{NH}_{4}\right)_{2} \mathrm{TiF}_{6}$ and $\mathrm{H}_{3} \mathrm{BO}_{3}$ were employed for $\mathrm{TiO}_{2}$ loading on activated carbon fibers (ACF), in reference to the report by Y. Hou et al. [13]. 
Surprisingly, the $\mathrm{TiO}_{\mathrm{x}} \mathrm{N}_{\mathrm{y}} \mathrm{C}$ obtained from ammonia nitridation at $1273 \mathrm{~K}$ showed the best catalytic activity for the electrochemical ORR in not only $\mathrm{HClO}_{4}$ (acidic) but also $\mathrm{KOH}$ (alkaline) aqueous solution. The reaction mechanism is also discussed, and that for alkaline solution is elucidated for the first time, to the best of our knowledge. The findings of this study will motivate the further development of an active electrode catalyst that can replace Pt.

\section{Experimental}

\subsection{Preparation and characterization of fibrous $\mathrm{TiO}_{\mathrm{x}} \mathrm{N}_{\mathrm{y}}-\mathrm{C}$ catalyst}

Activated carbon fiber bundles (ACF, AD'ALL, A-10, UNITICA LTD., Brunauer-Emmett-Teller surface area $=1,300 \mathrm{~m}^{2} \mathrm{~g}^{-1}$ ), cut to $\sim 1 \mathrm{~mm}$ lengths, were employed as fibrous substrates for LPD. An aqueous solution of $\left(\mathrm{NH}_{4}\right)_{2} \mathrm{TiF}_{6}(0.05 \mathrm{~mol}$ $\mathrm{dm}^{-3}$, Aldrich) was prepared in a polyethylene beaker. After complete dissolution of the titanate salt, $\mathrm{H}_{3} \mathrm{BO}_{3}\left(0.2 \mathrm{~mol} \mathrm{\textrm {dm } ^ { - 3 }}\right.$, Kishida Chemical Co.) was added. ACF was immediately dispersed in the solution, the vessel was sealed with a plastic lid, and the reaction was stirred vigorously for $24 \mathrm{~h}$. The sample was collected by vacuum filtration, 
mounted in an alumina boat, and heat treated in an electric tube furnace at $1273 \mathrm{~K}$ for 1 $\mathrm{h}$ under Ar.

Subsequent ammonia nitridation was carried out in an electric tube furnace equipped with a quartz glass tube under flowing ammonia (Iwatani, 99.9\%) at $1233 \mathrm{~K}$ for $2 \mathrm{~h}$. The heating rate was $5 \mathrm{~K} / \mathrm{min}$, and nitrogen gas was flowed up to $373 \mathrm{~K}$.

X-ray diffraction patterns (XRD; Rigaku, Geigerflex) were obtained before and after nitridation to investigate the composition and crystalline phase. The structure of the products was observed by field-emission scanning electron microscopy (FE-SEM; JEOL, JSM-6701F). The elemental composition was analyzed by energy dispersive Xray spectroscopy (EDS; JEOL, JED-2300) in conjunction with FE-SEM. Thermogravimetric analysis was carried out using a TG-DTA system (Rigaku, TG8120) under atmospheric air up to $1273 \mathrm{~K}$. The amount of $\mathrm{TiO}_{2}$ deposited by LPD was estimated from the residual weight after combustion of the ACF. The detailed chemical state of the product after nitridation was investigated by using X-ray photoelectron spectroscopy (XPS; ULVAC-PHI, PHI5000 VersaProbe). 


\subsection{Electrochemical oxygen reduction reaction study}

A rotating disk electrode (RDE) technique is generally employed to investigate intrinsic catalytic activity in the ORR among candidate catalysts. We applied the method proposed by T. J. Schmidt et al. to evaluate the catalytic activity of our catalyst in the ORR $[14,15]$. The product was ultrasonically dispersed in an aqueous solution containing ethanol and applied dropwise to a polished glassy carbon disk (Tokai Carbon) or a Ti metallic disk (Nilaco Corp.) for use in acidic or alkaline solutions, respectively. The disk diameters were $5 \mathrm{~mm}$. The catalyst loading on each disk electrode was $100 \mu \mathrm{g}$. To measure the ORR activity in acidic medium, a thin Nafion film was formed on the working electrode by casting the corresponding ionomer (Aldrich). In contrast, the anion exchange ionomer AS-4 (Tokuyama Corp.) was used for the activity measurements in alkaline medium. The calculated thicknesses of the Nafion and AS-4 layers were controlled to $80 \mathrm{~nm}$. For the acidic medium studies, a glass electrochemical cell was employed, and aqueous $\mathrm{HClO}_{4}$ solution $\left(0.1 \mathrm{~mol} \mathrm{dm}^{-3}\right.$, Kanto Chemical Co.), a reversible hydrogen electrode (RHE), and Au mesh were used as the electrolyte, reference electrode, and counter electrode, respectively. For the alkaline medium, the electrochemical cell was made of polytetrafluoroethylene. 
Aqueous $\mathrm{KOH}$ solution (0.1 mol dm${ }^{-3}$, Kishida), an $\mathrm{Hg} / \mathrm{HgO}$ electrode, and $\mathrm{Ni}$ mesh were employed as the electrolyte, reference electrode, and counter electrode, respectively. The potential is given versus the RHE. Electrochemical measurements were performed at $298 \mathrm{~K}$ with a potentiostat (ALS, model 700B). The current per unit weight of the sample (mass current density; $A \cdot \mathrm{g}^{-1}$ ) obtained under $\mathrm{N}_{2}$ atmosphere $\left(i_{\mathrm{N}}\right)$ subtracted from that under $\mathrm{O}_{2}$ atmosphere $\left(i_{\mathrm{O}}\right)$ was assumed to be responsible for the ORR. An AFMSRCE rotator (Pine Research Instrumentation) was used for the RDE.

\section{Results and Discussion}

\subsection{Characterization of fibrous $\mathrm{TiO}_{\mathrm{x}} \mathrm{N}_{\mathrm{y}}-\mathrm{C}$ catalyst}

The XRD pattern of the resultant material after $\mathrm{LPD}-\mathrm{TiO}_{2}$ deposition is shown in Figure $1 \mathrm{a}$ ). A broadened diffraction peak between $2 \theta=20$ and $25^{\circ}$ is assigned to the amorphous carbon structure originating from the ACF. A large diffraction peak corresponding to the highest peak assigned to anatase $\mathrm{TiO}_{2}$ (JCPDS No. 00-021-1272) only appears at $2 \theta=25.28^{\circ}$, clearly showing the formation of $\mathrm{TiO}_{2}$ by the LPD. Unfortunately, the other diffraction peaks corresponding to anatase $\mathrm{TiO}_{2}$ were not 
clearly visible. This may be related to not only the low crystallinity of the $\mathrm{TiO}_{2}$ as prepared, but also the low $\mathrm{TiO}_{2}$ content $(9 \mathrm{wt} \%)$, as estimated by thermogravimetric analysis-differential thermal analysis (TG-DTA) of the product. The sharp peak at $2 \theta=$ $\sim 27.48^{\circ}$ indicates rutile $\mathrm{TiO}_{2}$. Interestingly, the anatase $\mathrm{TiO}_{2}$ crystal structure persists even after heat treatment at $1273 \mathrm{~K}$; the anatase-to-rutile phase transition in $\mathrm{TiO}_{2}$ typically takes place when heated above $1188 \mathrm{~K}$ under inert atmosphere. Although the reasons for this remain unclear at present, $\mathrm{ACF}$ likely behaves as an inhibitor for the $\mathrm{TiO}_{2}$ phase transition.

The reactions for the formation of $\mathrm{TiO}_{2}$ during LPD are theoretically considered as follows [16-18]. $\mathrm{TiO}_{2}$ can be formed by hydrolysis of the $\mathrm{TiF}_{6}{ }^{2-}$ complex, as in Equation (1). The reaction is driven toward $\mathrm{TiO}_{2}$ formation in the presence of boric acid since fluoride anion is consumed by the formation of $\mathrm{BF}_{4}^{-}$[Equation (2)].

$\mathrm{TiF}_{6}^{2-}+2 \mathrm{H}_{2} \mathrm{O} \rightleftharpoons \mathrm{TiO}_{2}+6 \mathrm{~F}^{-}+4 \mathrm{H}^{+}$

$\mathrm{H}_{3} \mathrm{BO}_{3}+4 \mathrm{H}^{+}+4 \mathrm{~F}^{-} \rightarrow \mathrm{HBF}_{4}+3 \mathrm{H}_{2} \mathrm{O}$ 
Figure $1 \mathrm{~b}$ ) shows the XRD pattern of the product after nitridation at $973 \mathrm{~K}$. A large broadened peak assigned to graphite remained even after the heat treatment. In addition, a sharp peak due to rutile $\mathrm{TiO}_{2}$ was observed at $2 \theta=\sim 27.48^{\circ}, 36.09^{\circ}$ and 54.32 . As shown in Figure $1 \mathrm{c}$ ), the diffraction peaks derived from $\mathrm{TiO}_{2}$ and $\mathrm{ACF}$ disappear, and several peaks assigned to TiN are observed after ammonia nitridation at $1233 \mathrm{~K}$ for $2 \mathrm{~h}$. This result is consistent with those reported by Chisaka et al., who showed that XRD peaks corresponding to the TiN phase were mainly found after the ammonia nitridation of titanium carbonitride $\left(\mathrm{TiC}_{0.82} \mathrm{~N}_{0.23} \mathrm{O}_{0.06}\right)$ over $3 \mathrm{~h}$ at $1073 \mathrm{~K}$, whereas peaks attributable to rutile $\mathrm{TiO}_{2}$ were mainly observed below $973 \mathrm{~K}$ [19]. Similar results were observed in our study, as shown in Figs. 1 b) and c). In fact, after the ammonia nitridation was carried out at $973 \mathrm{~K}$, residual rutile $\mathrm{TiO}_{2}$ and the absence of the TiN phase were confirmed by XRD measurement [Fig. 1 b)], which clearly shows that nitridation did not take place below this temperature. Thus, it is reasonable to consider, as reported by Chisaka et al., that the nitridation degree (as indicated by the appearance of the TiN phase) is dependent on the ammonia nitridation temperature [19]. On the other hand, if the ammonia nitridation temperature was higher 
than $1233 \mathrm{~K}$, the ACF would be severely decomposed and the products would be unable to fully retain a fibrous structure.

The presence of $\mathrm{O}-\mathrm{Ti}-\mathrm{O}, \mathrm{Ti}-\mathrm{N}, \mathrm{Ti}-\mathrm{O}-\mathrm{N}$, and $\mathrm{O}-\mathrm{Ti}-\mathrm{N}$ bonding was evident in the $\mathrm{Ti}_{2 \mathrm{p}}$ XPS spectrum of the product at $1233 \mathrm{~K}$. The $\mathrm{Ti}_{2 \mathrm{p}}, \mathrm{C}_{1 \mathrm{~s}}, \mathrm{~N}_{1 \mathrm{~s}}$, and $\mathrm{O}_{1 \mathrm{~s}}$ spectra are shown in Figure 2. Each peak was identified based on the literature [20-26]. The appearance of $\mathrm{Ti}-\mathrm{O}-\mathrm{N}$ and $\mathrm{O}-\mathrm{Ti}-\mathrm{N}$ bonding in the $\mathrm{Ti}_{2 p}$ spectrum clearly indicates the formation of $\mathrm{TiO}_{\mathrm{x}} \mathrm{N}_{\mathrm{y}}$. Although we have not yet been able to measure the nitrogen content, some portion of $\mathrm{TiO}_{2}$ was likely converted to $\mathrm{TiN}$ by nitridation, as reported by Chisaka et al. [19]. A peak fraction presumably attributable to pyridine-like C-N bonding is observed in the $\mathrm{N}_{1 \mathrm{~s}}$ spectrum; however, its formation cannot be confirmed in the $\mathrm{C}_{1 \mathrm{~s}}$ spectrum because of the overlap of the peaks assigned to several kinds of $\mathrm{C}$ and O bonding modes [25]. Nevertheless, the $\mathrm{N}_{1 \mathrm{~s}}$ spectrum strongly suggests that pyridinetype $\mathrm{C}-\mathrm{N}$ bonds are formed during ammonia nitridation [26]. The atomic ratio of $\mathrm{C}, \mathrm{N}$, $\mathrm{O}$, and $\mathrm{Ti}$ after nitridation at $1233 \mathrm{~K}$ was measured by EDS as 35:46:15:4. The relatively high nitrogen composition should correspond to the formation of the TiN phase that was introduced to the ACF, which would lead to the formation of $\mathrm{C}-\mathrm{N}$ bonding. Carbon was also probably introduced into the titania oxynitride layer during 
ammonia nitridation and would influence the ORR activity; unfortunately, it is hardly possible to measure the carbon content due to its low abundance as well as the ACF remaining after the nitridation [Fig. 3].

A FE-SEM image of the sample after LPD [Figure 3 a)] shows that $\mathrm{TiO}_{2}$ particles were thickly deposited on the ACF surface. In addition, particles of several hundred nanometers in size were observed. Figure 3 b) shows the FE-SEM image of the lateral face of the product after ammonia nitridation at $1233 \mathrm{~K}$. The fibrous morphology with the precipitates on the surface is recognizable as "pyrrosia piloselloides." The fibers with the surface-bound precipitates resemble fine lace, forming not only a network structure but also a large number of pores. These may allow the rapid diffusion of reactants, and increase the active surface area inside the catalyst $[11,12]$. The edge face is shown in Fig. 3 c). The ACF remains as a core even after the heat treatment, although the weight of the ACF was reduced and its diameter decreased by ca. $50 \%$. The reduction in weight as well as diameter suggests decomposition of the ACF during ammonia nitridation. 


\subsection{Hydrodynamic voltammograms in $\mathrm{HClO}_{4}$ and $\mathrm{KOH}$ aqueous solutions}

In Fig. 4, the solid line "a)" shows the voltammogram for the ORR in $\mathrm{HClO}_{4}$

solution obtained at $1600 \mathrm{rpm}$. An enlargement of the region between 0.6 and $1.0 \mathrm{~V}$ is shown in the lower panel. An appreciable reduction current was observed below ca. $0.85 \mathrm{~V}$ in the voltammogram, demonstrating that the product has intrinsic catalytic activity for $\mathrm{ORR}$ in $\mathrm{HClO}_{4}$ solution.

Surprisingly, the product also catalyzes the ORR in $\mathrm{KOH}$ solution. The dashed line "b)" shows the hydrodynamic voltammogram of the product in alkaline medium. A high onset potential approaching that of $\mathrm{Pt}$ was determined by the appreciable reduction current after $0.95 \mathrm{~V}$ [27]. Ohnishi et al. investigated the ORR activity of TiN nanoparticles in $0.1 \mathrm{~mol} \mathrm{dm}^{-3} \mathrm{NaOH}$ solution [28], and found an onset potential of 0.85 $\mathrm{V}$ vs. RHE for the prepared TiN nanoparticles, although commercial TiN (>100 nm in size) did not exhibit activity. To the best of our knowledge, the number of ORR studies for titania analogs in alkaline versus acidic media is limited, and studies concerned with kinetics and mechanism are especially rare. In the following section, we attempt a detailed discussion of the ORR mechanism of our catalyst. 


\subsection{Discussion of the oxygen reduction reaction in $\mathrm{HClO}_{4}$ aqueous solution}

In electrochemical kinetics, the Tafel equation relates the current of an

electrochemical reaction to the overpotential $(\eta)$, as given by

$\eta=a+b \log i_{\mathrm{d}}$

Here, $a, b$, and $i_{\mathrm{d}}$ are the Tafel constant, the slope, and the current density, respectively.

The slope is considered in this study since it provides information about the reaction

mechanism and identifies the rate-determining step of the overall reaction. The Tafel equation enables the estimation of the kinetic parameters for the ORR when the overpotential is below $1.102 \mathrm{~V}$, since the theoretical potential is $1.22 \mathrm{~V}$.

The $i R$-corrected Tafel plots for the $\mathrm{HClO}_{4}$ solution are shown in Figure 5 a). The slope is $\sim 240 \mathrm{mV} \mathrm{dec}{ }^{-1}$ in the $0.9-0.65 \mathrm{~V}$ range, in good agreement with that reported for the reduction of $\mathrm{H}_{2} \mathrm{O}_{2}$ on a gold electrode [29]. The cathodic ORR is well known as a multi-electron reaction associated with the formation of reaction intermediates. The most commonly considered reaction mechanism was proposed by Damjanovic et al. [6]. When the voltammetry experiment is performed in the anodic 
direction from 0.05 to $1.0 \mathrm{~V}, \mathrm{H}_{2} \mathrm{O}_{2}$ would be produced at a potential below $0.67 \mathrm{~V}$ vs.

SHE according to

$\mathrm{O}_{2}+2 \mathrm{H}^{+}+2 \mathrm{e}^{-} \rightarrow \mathrm{H}_{2} \mathrm{O}_{2}$

and then further reduced and/or decomposed to water

$\mathrm{H}_{2} \mathrm{O}_{2}+2 \mathrm{H}^{+}+2 \mathrm{e}^{-} \rightarrow 2 \mathrm{H}_{2} \mathrm{O}$

Therefore, in this case, the mechanism of ORR is considered to include reactions (4) and (5) rather than a direct four electron reaction as reported for $\mathrm{Pt}$ in acidic medium [equation (6)].

$\mathrm{O}_{2}+4 \mathrm{H}^{+}+4 \mathrm{e}^{-} \rightarrow 2 \mathrm{H}_{2} \mathrm{O}$

In theory, $\mathrm{H}_{2} \mathrm{O}_{2}$ is not thermodynamically produced above $0.67 \mathrm{~V}$ vs. RHE. Thus, to investigate the activity for the direct four electron transfer pathway [equation (6)], the 
Tafel slope was obtained above $0.70 \mathrm{~V}$ from the voltammogram in the cathodic direction [Figure $5 \mathrm{a}$ ), circle symbols]. The slope, $\sim 158 \mathrm{mV} \operatorname{dec}^{-1}$ in the $0.85-0.70 \mathrm{~V}$ range, is larger than that of $\mathrm{Pt}\left(60\right.$ and $120 \mathrm{mV} \mathrm{dec}^{-1}$ for lower and higher overpotential regions, respectively) and suggests (unfortunately) a lower catalytic activity [4-6]. The lower ORR activity of our product might be the result of physicochemical properties such as low crystallinity and low surface area, or even the formation of a large TiN phase $[19,30]$. Improvement in the catalytic activity might be achieved by optimization of the mass fraction of active sites, which is a key feature in determining ORR activity $[19,30]$.

\subsection{Discussion of the oxygen reduction reaction in $\mathrm{KOH}$ aqueous solution}

The $i R$-corrected Tafel plots for the $\mathrm{KOH}$ medium are shown in Figure $5 \mathrm{~b}$ ). The plots exhibit two different slopes, -123 and $-239 \mathrm{mV} \mathrm{dec}^{-1}$ at $0.95-0.8 \mathrm{~V}$ and $0.8-0.65$ $\mathrm{V}$, respectively. The larger slope may involve the mass transport of oxygen. The mechanism for the ORR can be elucidated as either a direct four-electron pathway [equation (7)] or a peroxide intermediate pathway [equation (8) and (9)] [4-6]. 
$\mathrm{O}_{2}+4 \mathrm{H}^{+}+4 \mathrm{e}^{-} \rightarrow 4 \mathrm{OH}^{-}$

$\mathrm{O}_{2}+\mathrm{H}_{2} \mathrm{O}+2 \mathrm{e}^{-} \rightarrow \mathrm{HO}_{2}^{-}+\mathrm{OH}^{-}$

$\mathrm{HO}_{2}^{-}+\mathrm{H}_{2} \mathrm{O}+2 \mathrm{e}^{-} \rightarrow 3 \mathrm{OH}^{-}$

Equation (7) was proposed as the mechanism for a Pt-mediated reaction in which the Tafel slope was reported as $60 \mathrm{mV} \mathrm{dec}-1$ [4-6, 27]. The mechanism that includes equations (8) and (9) has been proposed for graphite (and most carbonaceous materials), gold, most oxide-covered metals ( $\mathrm{Ni}, \mathrm{Co}$ ), most transition metal oxides, and transition metal macrocycles $[4,5]$. In the case of gold and stress-annealed pyrolitic graphite, the Tafel slope was $120 \mathrm{mV} \mathrm{dec}{ }^{-1}$, which is very close to our result in the $0.95-0.8 \mathrm{~V}$ region [4-6]. Even though it is difficult to determine the reaction mechanism from only the Tafel slope, the ORR mechanism in alkaline solution is not likely to be the direct fourelectron pathway, but rather, the peroxide intermediate pathway. Therefore, the ratedetermining step of the ORR for our catalyst in $\mathrm{KOH}$ solution is assumed to be [4-6]

$\mathrm{O}_{2(\mathrm{ads})}+\mathrm{e}^{-} \rightarrow \mathrm{O}_{2}{ }^{-}$(ads) 
where (ads) indicates "adsorption at the active site". Equation (11) should follow:

$2 \mathrm{O}_{2}^{-}{ }_{(\mathrm{ads})}+\mathrm{H}_{2} \mathrm{O} \rightarrow \mathrm{O}_{2}+\mathrm{HO}_{2}^{-}+\mathrm{OH}^{-}$

In turn, the onset potential for the ORR should be determined at $0.95 \mathrm{~V}$, as the curve has a reasonable slope there in the Tafel plots.

In this study, we prepared an electrode catalyst with a fibrous, porous morphology via the LPD of $\mathrm{TiO}_{2}$ on $\mathrm{ACF}$ followed by heat treatment and ammonia nitridation. As determined by the onset potential, the catalyst shows ORR activity in both acid and alkaline media, and approaches that of Pt in the latter. This catalyst contains only the highly abundant elements $\mathrm{C}, \mathrm{O}, \mathrm{N}$, and $\mathrm{Ti}$, which will reduce both the costs and material limitations of the electrochemical power sources that use oxygen as a reactant. Although the present catalytic activity of our product for the ORR is insufficient, we expect that further studies of its active sites, crystallinity, and surface area will afford significant improvement. 


\section{Conclusion}

A fibrous catalyst composed of titania oxynitride and activated carbon fibers

$\left(\mathrm{TiO}_{\mathrm{x}} \mathrm{N}_{\mathrm{y}}-\mathrm{C}\right)$ was prepared and its catalytic activity and the reaction mechanism for the

ORR were investigated in both $\mathrm{HClO}_{4}$ (acidic) and $\mathrm{KOH}$ (alkaline) solutions.

The results of the XRD and XPS analyses revealed the formation of $\mathrm{TiO}_{\mathrm{x}} \mathrm{N}_{\mathrm{y}}$ and

TiN. In particular, $\mathrm{O}-\mathrm{Ti}-\mathrm{O}, \mathrm{Ti}-\mathrm{N}, \mathrm{Ti}-\mathrm{O}-\mathrm{N}$, and $\mathrm{O}-\mathrm{Ti}-\mathrm{N}$ bonds were recognized by XPS. FE-SEM observation revealed a fibrous morphology with a networked structure of precipitates on the fiber surface and a large number of internal pores.

The RDE study showed that the prepared $\mathrm{TiO}_{\mathrm{x}} \mathrm{N}_{\mathrm{y}}-\mathrm{C}$ catalyzes the ORR in both $\mathrm{HClO}_{4}$ and $\mathrm{KOH}$ aqueous solutions. The onset potential in $\mathrm{HClO}_{4}$ solution is assumed to be moderate at $0.85 \mathrm{~V}$. On the other hand, the onset potential for the ORR was determined, for the first time, to be at $0.95 \mathrm{~V}$ in $\mathrm{KOH}$ solution, where the curve has a reasonable slope in the Tafel plot, and which surprisingly approximates that of Pt. Furthermore, it is considered from the Tafel plot analysis that the ORR mechanism in $\mathrm{KOH}$ solution follows a peroxide intermediate pathway and the rate-determining step would be a one-electron transfer to oxygen molecules adsorbed at the active site. 


\section{Acknowledgements}

This work was supported by the "Advanced Low Carbon Technology Research and Development Program (ALCA), Development of Metal Hydride/Air Secondary Battery" of the Japan Science and Technology Agency (JST), and Research Project A of the Venture Business Laboratory of Oita University. ACF and AS-4 were generously supplied by UNITICA LTD and the Tokuyama Corporation, respectively.

\section{References}

[1] N. Imanishi, O. Yamamoto, Mater. Today, 17 (2014) 24-30.

[2] M. Winter, R. J. Brodd, Chem. Rev., 104 (2004) 4245-4269.

[3] M. Morimitsu, T. Kondo, K. Takano, Electrochem., 5 (2010) 493-496.

[4] K. Kinoshita, Electrochemical Oxygen Technology, John Wiley \& Sons, Inc., 1992, pp. 19-40.

[5] E. Yeager, Electrochim. Acta, 29 (1984) 1527-1537.

[6] A. Damjanovic, M. Genshaw, J. Bockris, J. Phys. Chem., 70 (1966) 3761-3762. 
[7] J. H. Kim, A. Ishihara, S. Mitsushima, N. Kamiya, K. Ota, Electrochim. Acta, 52 (2007) 2492-2497.

[8] Y. Ohgi, A. Ishihara, Y. Shibata, S. Mitsushima, K. Ota, Chem. Lett., 37 (2008) 608-609.

[9] K. Ota, Y. Ohgi, K. D. Nam, K. Matsuzawa, S. Mitsushima, A. Ishihara, J. Power Sources, 196 (2011) 5256-5263.

[10]F. Jaouen, J. Herranz, M. Lefevre, J. P. Dodelet, U. I. Kramm, I. Herrmann, P. Bogdanoff, J. Maruyama, T. Nagaoka, A. Garsuch, J. R. Dahn, T. Olson, S. Pylypenko, P. Atanassov, E. A. Ustinov, ACS Appl. Mater. Interfaces, 1 (2009) 1623-1639.

[11]M. K. Debe, A. K. Schmoeckel, G. D. Vernstrom, R. Atanasoski, J. Power Sources, 161 (2006) 1002-1011.

[12] S. Murata, M. Imanishi, S. Hasegawa, R. Namba, J. Power Sources, 253 (2014) 104-113.

[13] Y. Hou, J. Qu, X. Zhao, P. Lei, D. Wan, C. P. Huang, Sci. Total Environ., 407 (2009) 2431-2439. 
[14] T. J. Schmidt, H. A. Gasteiger, G. D. Stab, P. M. Urban, D. J. Kolb, R. J. Behm, J. Electrochem. Soc., 145 (1998) 2354-2358.

[15]U. A. Paulus, T. J. Schmidt, H. A. Gasteiger, R. J. Behm, J. Electroanal. Chem., 495 (2001) 134-145.

[16]S. Deki, N. Yoshida, Y. Hiroe, K. Akamatsu, M. Mizuhata, A. Kajinami, Solid State Ionics, 151 (2002) 1-9.

[17]S. Deki, S. Iizuka, M. Mizuhata, A. Kajinami, J. Electroanal. Chem., 584 (2005) $38-43$.

[18] T. Kinumoto, K. Nagano, Y. Yamamoto, T. Tsumura, M. Toyoda, J. Power Sources, 249 (2014) 503-508.

[19] M. Chisaka, A. Ishihara, K. Suito, K. Ota, H. Muramoto, Electrochim. Acta, 88 (2013) 697-707.

[20] K. S. Robinson, P. M. A. Sherwood, Surface Interface Anal., 6 (1984) 261-266.

[21]N. C. Saha, H. G. Tompkins, J. Appl. Phys., 72 (1992) 3072-3079.

[22]X. Chen, C. Burda, J. Phys. Chem. B, 108 (2004) 15446-15449.

[23] Y. Cong, J. Zhang, F. Chen, M. Anpo, J. Phys. Chem. C, 111 (2007) 6976-6982.

[24]B. Avasarala, T. Murray, W. Li, P. Haldar, J. Mater. Chem., 19 (2009) 1803-1805. 
[25]H. Choo, T. Kinumoto, S. K. Jeong, Y. Iriyama, T. Abe, Z. Ogumi, J. Electrochem. Soc., 154 (2007) B1017-1023.

[26]E. Raymundo-Piñero, D. Cazorla-Amorós, A. Linares-Solano, J. Find, U. Wild, R. Schlögl, Carbon, 40 (2002) 597-608.

[27]F. H. B. Lima, J. Zhang, M. H. Shao, K. Sasaki, M. B. Vukmirovic, E. A. Ticianelli, R. R. Adzic, J. Phys. Chem. C, 111 (2007) 404-410.

[28]R. Ohnishi, M. Katayama, D. Cha, K. Takanabe, J. Kubota, K. Domen, J. Electrochem. Soc., 160 (2013) F501-F506.

[29]R. Zeis, T. Lei, K. Sieradzki, J. Snyder, J. Erlebacher, J. Catal., 253 (2008) 132138.

[30] M. Chisaka, A. Ishihara, K. Ota, H. Muramoto, Electrochim. Acta, 113 (2013) 735740. 


\section{Figure captions}

Figure 1. X-ray diffraction patterns of the product a) after $\mathrm{LPD}-\mathrm{TiO}_{2}$ deposition, and after subsequent ammonia nitridation at b) $973 \mathrm{~K}$ and c) $1233 \mathrm{~K}$. Standard patterns for d) graphite (JCPDS 00-041-1487), e) anatase $\mathrm{TiO}_{2}$ (JCPDS 00-021-1272), f) rutile $\mathrm{TiO}_{2}$ (JCPDS 00-021-1276) and g) TiN (JCPDS 00-038-1420).

Figure 2. X-ray photoelectron spectra of the product: a) $\mathrm{Ti}_{2 \mathrm{p}}$, b) $\mathrm{C}_{1 \mathrm{~s}}$, c) $\mathrm{N}_{1 \mathrm{~s}}$, and c) $\mathrm{O}_{1 \mathrm{~s}}$.

Figure 3. FE-SEM images of the product a) after $\mathrm{LPD}^{-\mathrm{TiO}_{2}}$ deposition. b) Lateral and c) edge faces after subsequent ammonia nitridation.

Figure 4. Hydrodynamic voltammograms of the product in a) $\mathrm{HClO}_{4}$ (solid line) and b) $\mathrm{KOH}$ (dashed line) aqueous solutions (upper). Enlargement of the 0.6-1.0 V region (lower).

Figure 5. Tafel plots of the product in a) $\mathrm{HClO}_{4}$ and b) $\mathrm{KOH}$ aqueous solutions. Square and circle symbols in a) show plots obtained in the anodic and cathodic voltammetry directions. 


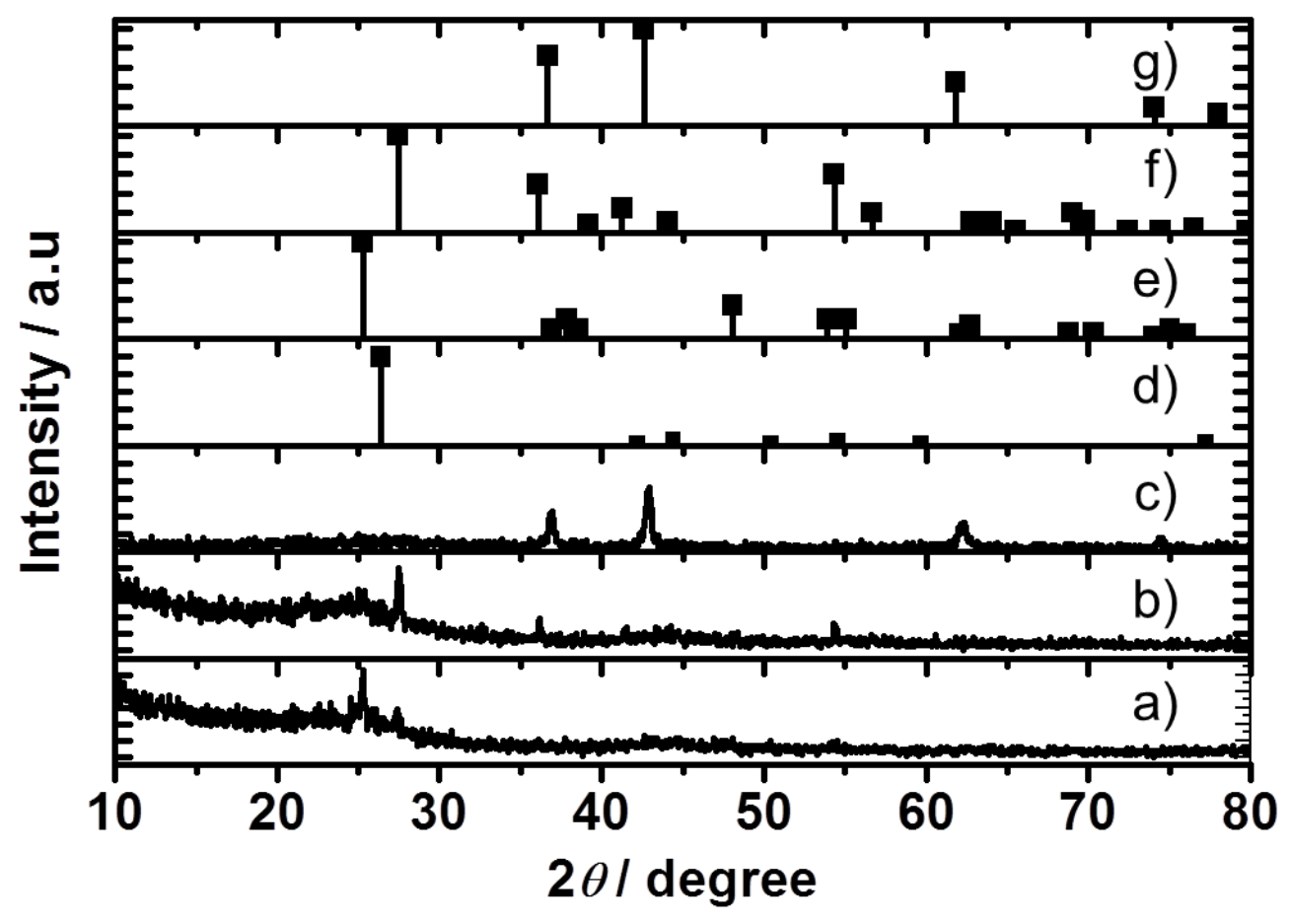

Figure 1. X-ray diffraction patterns of the product a) after $\mathrm{LPD}-\mathrm{TiO}_{2}$ deposition, and after subsequent ammonia nitridation at b) $973 \mathrm{~K}$ and c) $1233 \mathrm{~K}$. Standard patterns for d) graphite (JCPDS 00-041-1487), e) anatase $\mathrm{TiO}_{2}$ (JCPDS 00-021-1272), f) rutile $\mathrm{TiO}_{2}$ (JCPDS 00-021-1276) and g) TiN (JCPDS 00-038-1420).

T. Kinumoto et al., Fig. 1 

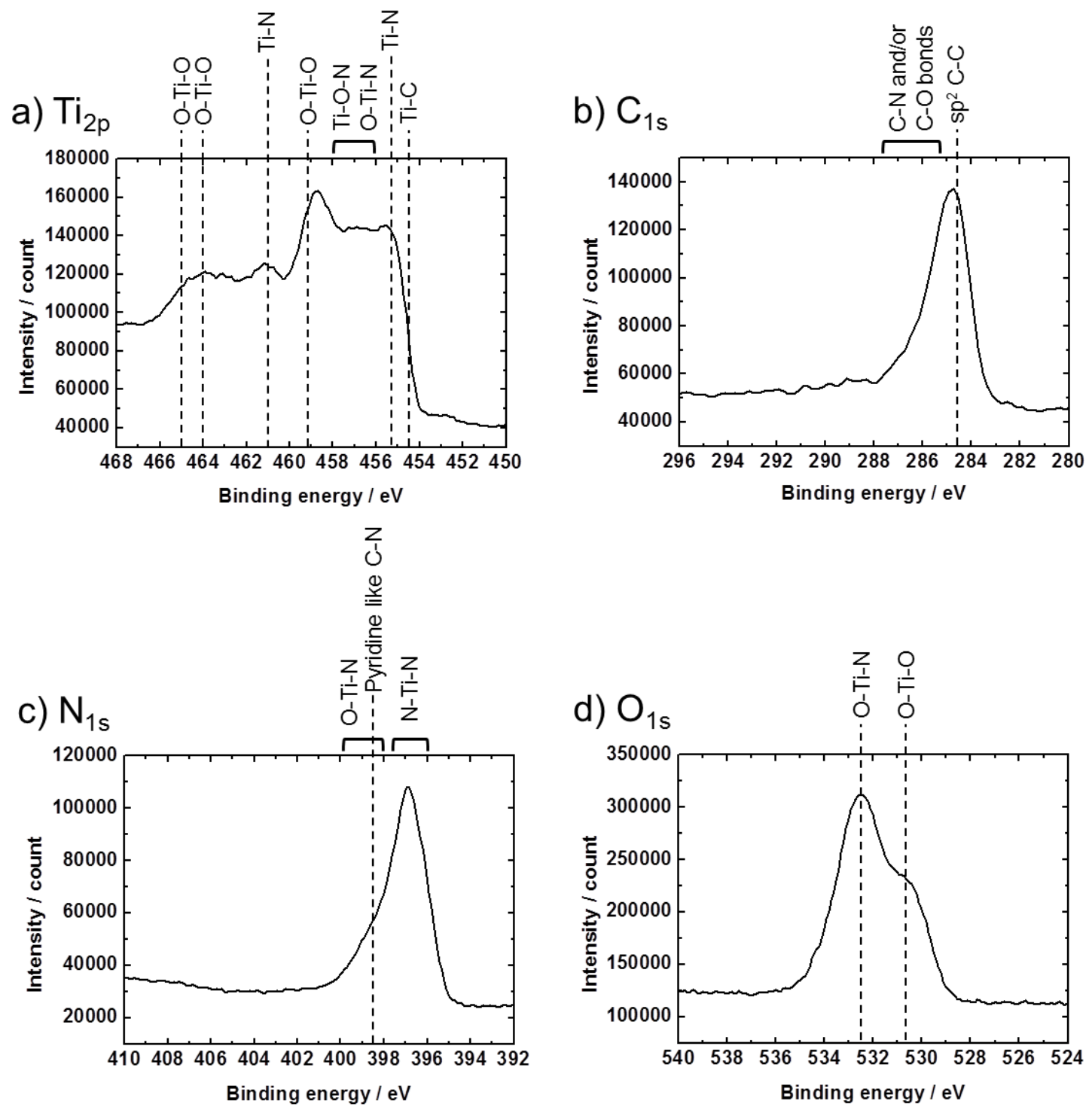

Figure 2. X-ray photoelectron spectra of the product: a) $\mathrm{Ti}_{2 \mathrm{p}}$, b) $\left.\mathrm{C}_{1 \mathrm{~s}}, \mathrm{c}\right) \mathrm{N}_{1 \mathrm{~s}}$, and c) $\mathrm{O}_{1 \mathrm{~s}}$. 


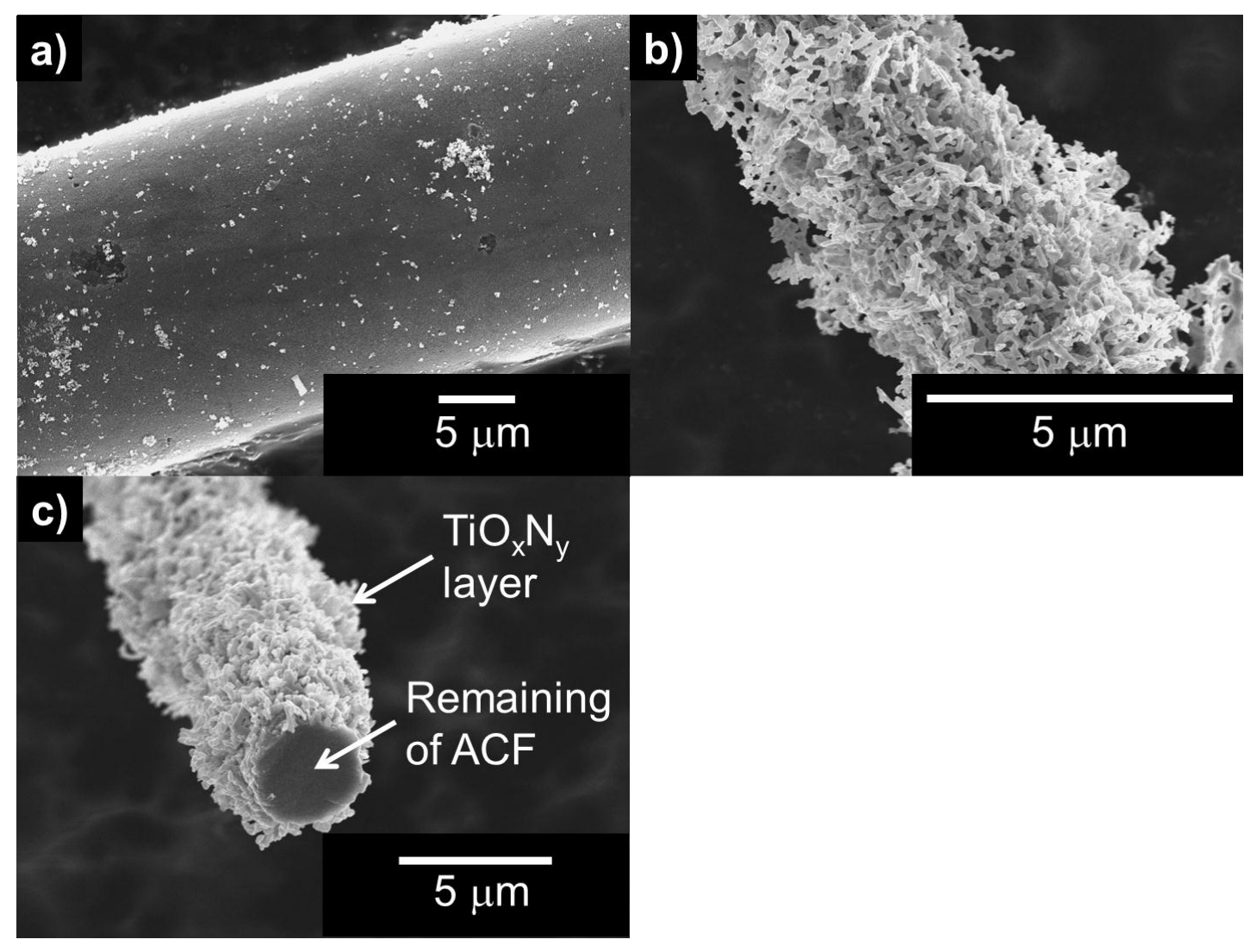

Figure 3. FE-SEM images of the product a) after $\mathrm{LPD}-\mathrm{TiO}_{2}$ deposition. b) Lateral and c) edge faces after subsequent ammonia nitridation.

T. Kinumoto et al., Fig. 3 

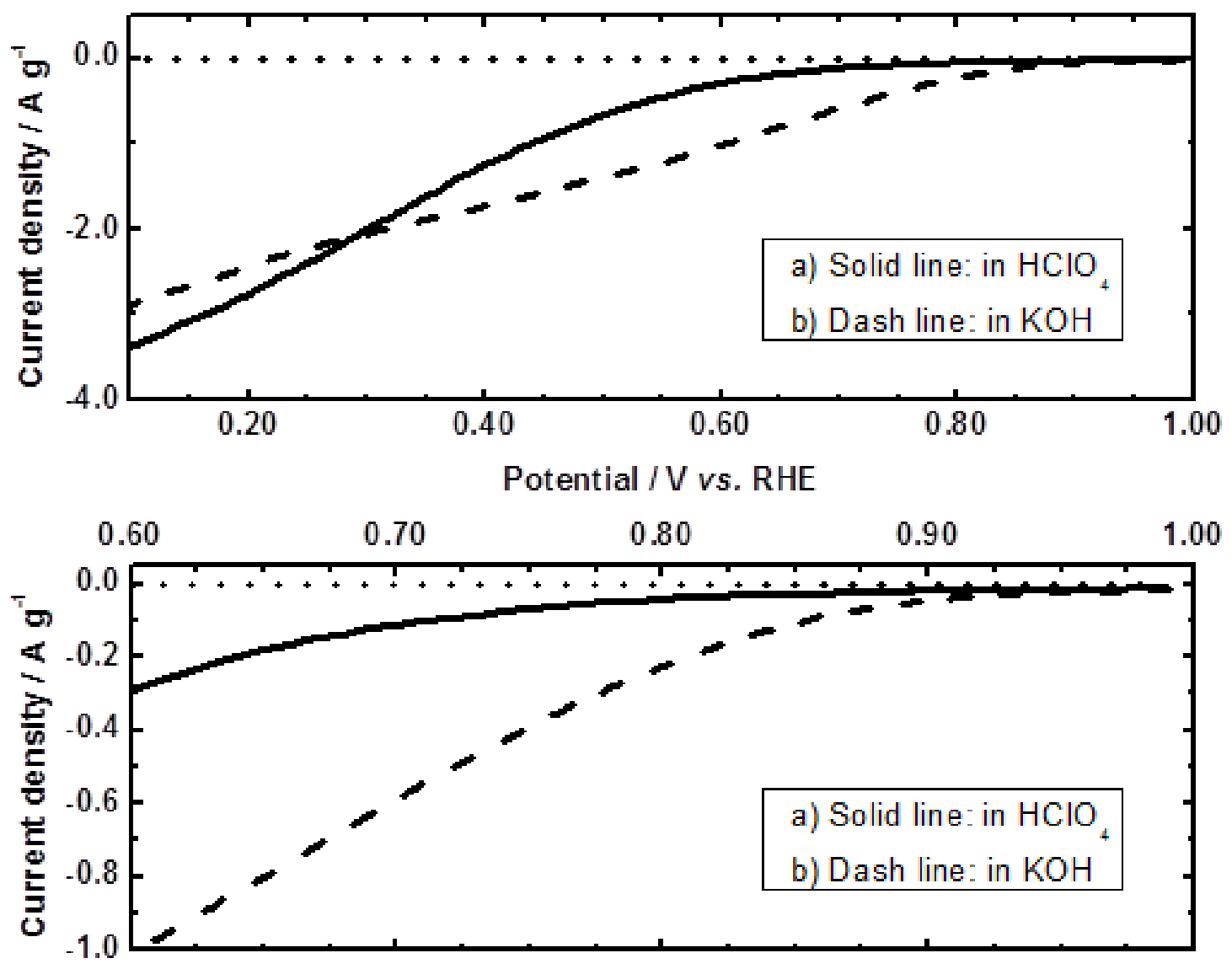

Figure 4. Hydrodynamic voltammograms of $\mathrm{TiO}_{x} \mathrm{~N}_{\mathrm{y}} \mathrm{C}$ in a) $\mathrm{HClO}_{4}$ (solid line) and b) $\mathrm{KOH}$ (dashed line) aqueous solutions (upper). Enlargement of the 0.6-1.0 V region (lower).

T. Kinumoto et al., Fig. 4 

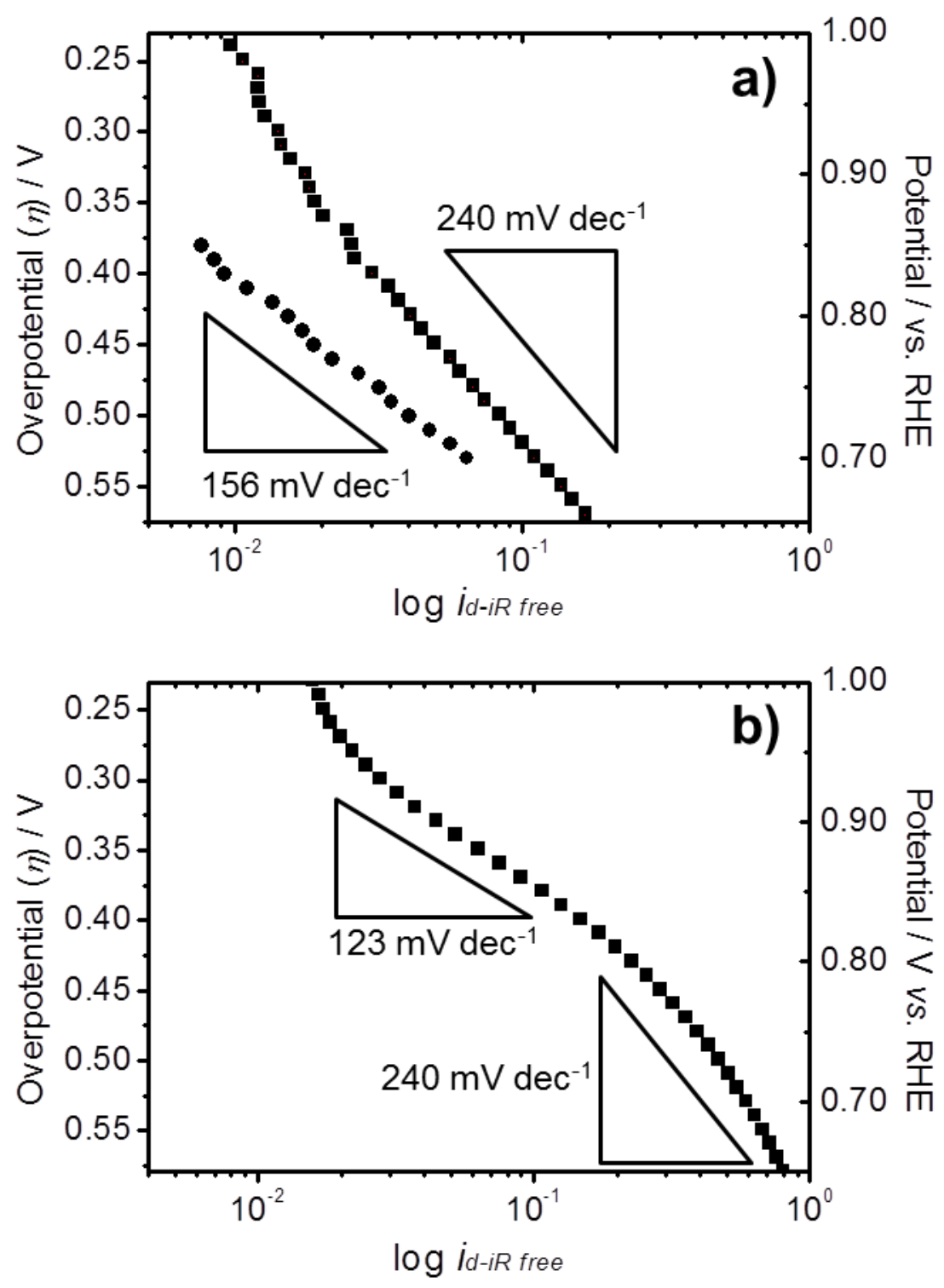

Figure 5. Tafel plots of $\mathrm{TiO}_{x} \mathrm{~N}_{y}-\mathrm{C}$ in a) $\mathrm{HClO}_{4}$ and b) $\mathrm{KOH}$ aqueous solutions. Square and circle symbols in a) show plots obtained in the anodic and cathodic voltammetry directions. 